\title{
Ankyloglossia: Treatment With Surgical Lasers - A Case Report
}

\author{
Dr Tanya ${ }^{1}$, Dr. Priya Lele ${ }^{2}$, Dr. Pallavi Patil ${ }^{2}$ \\ ${ }^{I}$ (Department Periodontology, Manubhai Patel dental Dental College And Hospital, Vadodara India) \\ ${ }_{2}^{2}$ (Department of Periodontology Bharati Vidyapeeth Deemed University Dental College And Hospital, Pune, \\ India)
}

\begin{abstract}
Ankyloglossia or tongue tie is a developmental anomaly of the tongue characterized by an abnormally short, thick lingual frenum resulting in limitation of tongue movement. Ankyloglossia can adversely affect feeding, speech articulation, and oral hygiene maintenance. The lingual frenum is interposed between a highly mobile tongue and a richly vascular floor of mouth. In such situation, frenectomy with laser is more advantageous over conventional scalpel method.

This case reports of a 35-year-old male with tongue-tie who complained of difficulty in speech following which he underwent lingual frenectomy procedure with laser, without any complications. Finally, he was given speech therapy sessions.
\end{abstract}

Keywords: Ankyloglossia, LASERs, Lingual frenectomy, Tongue tie.

\section{Introduction}

The soft tissue that attaches the underside of the tongue to the floor of the mouth is referred to as the lingual frenum. This attachment binds the tip of the tongue to the posterior (back) surface of the mandible (lower jaw). (tongue)

Etymologically, "ankyloglossia" originates from the Greek words "agkilos" (curved) and "glossa"

The first use of the term 'Ankyloglossia' in the medical literature dates back to the 1960s, when Wallace (1963) ${ }^{[1]}$ defined tongue-tie as "a condition in which the tip of the tongue cannot be protruded beyond the lower incisor teeth because of a short frenulum linguae, often containing scar tissue". Ankyloglossia severity can range from a slight abnormality with no clinical significance to a tongue completely fixed to the floor of the mouth. Incidence of ankyloglossia is $4.8 \%$ and effects more males at almost a 3:1 ratio. ${ }^{[2]}$ An abnormally short lingual frenum results in difficulties in speech and oral hygiene maintenance, development of gingival recession on the lingual side of the lower front teeth(lingual), and also interferes with the stability of mandibular prosthesis (denture). ${ }^{[3]}$

\section{Case Report:}

A 35-year-old male reported to the Department of Periodontology, Bharati Vidyapeeth Dental College and Hospital, Pune with complaint of bleeding gums. Complete medical and dental history was recorded and a detailed extra-oral and intra-oral examination was done. The general physical examination was normal. On intraoral examination, generalized grade II calculus was present and the subject was scheduled for scaling procedure. It was also found that the subject had ankyloglossia and was classified as Class III by utilizing Kotlow's (1999) ${ }^{[4]}$ assessment (Fig.1). There was slight crowding present but no lingual recession in mandibular incisors. A lingual frenectomy procedure was planned using the diode laser method under local anesthesia $(2 \%$ lignocaine hydrochloride and 1:80,000 adrenaline). The lingual frenum was clamped using two mosquito haemostats and care was taken with regard to position of the sublingual caruncle. Two incisions, using contact mode with diode laser (Biolase ${ }^{\circledR}$ ), were made, one at the superior aspect of the upper haemostat and the second at inferior aspect of the lower haemostat (Fig.2). In this way the intervening frenum was excised resulting in a diamond shaped wound. (Fig.3). Submucosal dissection was done on lower border, so as to achieve a tension free closure of the wound edges. 3 interrupted sutures were given using (4-0) black braided silk sutures (Fig.4). This allowed for the tissues to heal by primary intention thereby minimizing the scar tissue formation. No sutures were given on the upper border of the wound. Antibiotics and analgesics were prescribed to prevent post-operative infection and pain. Sutures were removed after 1 week (Fig.5). The patient was referred for speech therapy sessions. After a follow-up of 3 months, sublingual region showed good healing (Fig 6). The subject could protrude his tongue several millimetres beyond the lower lip and had improved speech. 


\section{Discussion:}

Oral developmental problems that can be easily diagnosed and treated in the dental office are the abnormal attachments of the maxillary frenum and lingual frenum. Ankyloglossia is the result of a failure in cellular degeneration leading to a much longer anchor between the floor of the mouth and the tongue. ${ }^{[5]}$

Suggested classification of tongue-ties: (based on distance of the insertion of the lingual frenum to the tip of the tongue) ${ }^{[4]}$

Clinically acceptable, normal range of free tongue: greater than $16 \mathrm{~mm}$

Class I: Mild ankyloglossia: 12 to $16 \mathrm{~mm}$

Class II: Moderate ankyloglossia: 8 to $11 \mathrm{~mm}$

Class III: Severe ankyloglossia: 3 to $7 \mathrm{~mm}$

Class IV: Complete ankyloglossia: less than $3 \mathrm{~mm}$

Class III and IV tongue-tie category should be given special consideration because they severely restrict tongue movement. A normal range of motion of the tongue is indicated by the following criteria: the tip of the tongue should be able to protrude outside the mouth without clefting, the tip of the tongue should be able to sweep the upper and lower lips easily without straining, the tongue when retruded should not blanch the tissues lingual to the anterior teeth and the lingual frenum should not create a diastema between the mandibular central incisors.

Surgical techniques for the therapy of tongue-ties can be classified into three procedures. Frenotomy is a simple cutting of the frenulum. Frenectomy is defined as complete excision of the whole frenulum. Frenuloplasty involves various methods to release the tongue-tie and correct the anatomic situation. ${ }^{[5]}$ These procedures are conventionally carried out with help of surgical scapel. But it can be with the help of soft tissue LASERs also.

There are several advantages to using LASERs in surgical therapy. Wigdor et al (1995) ${ }^{[6]}$ described the advantages of LASERs over cold steel surgical procedures as follows:

1. Dry and bloodless surgery

2. Instant sterilization of the surgical site

3. Reduced bacteremia

4. Reduced mechanical trauma

5. Minimal postoperative swelling and scarring

6. Minimal postoperative pain

In his discussion of soft tissue surgery, Bader (2000) ${ }^{[7]}$ listed the same advantages and specified that when performing frenectomies in younger patients, the laser is particularly benign compared with traditional surgery. Since floor of the mouth is a highly vascularised, using surgical LASERs in this area for incision is advantageous as they provide excellent hemostasis (therefore a clear field to operate) and the need for suturing is reduced significantly.

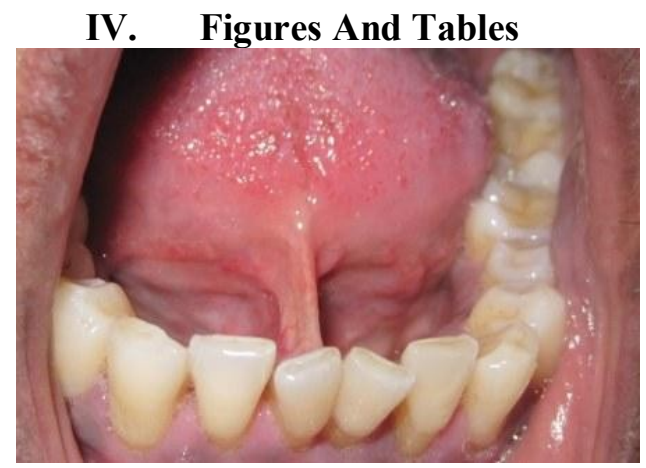

Figure 1. Pre-operative view of subject with Kotlow's Class III ankyloglossia. 


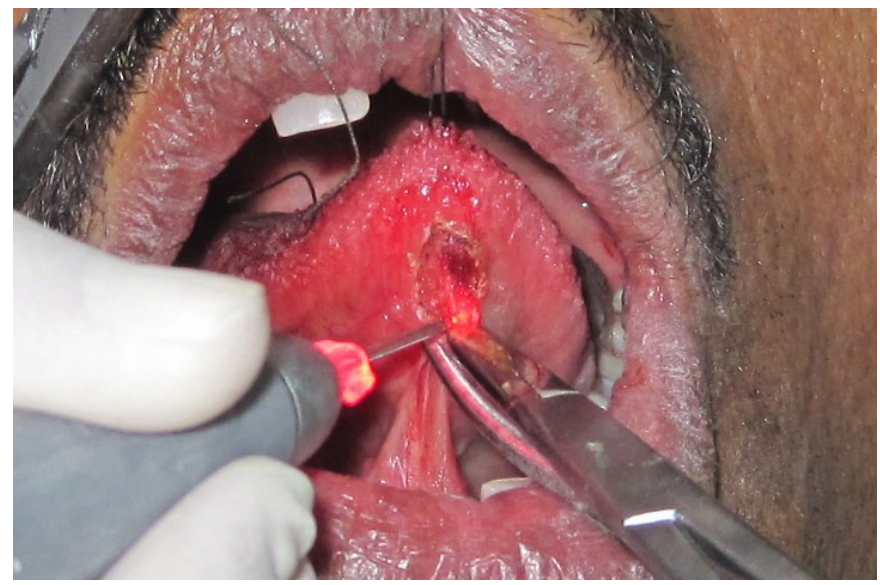

Figure 2. Incision being by diode LASERs.

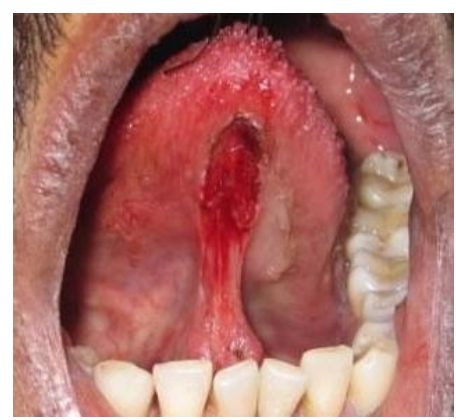

Figure 3. Diamond shaped wound post frenulum excision.

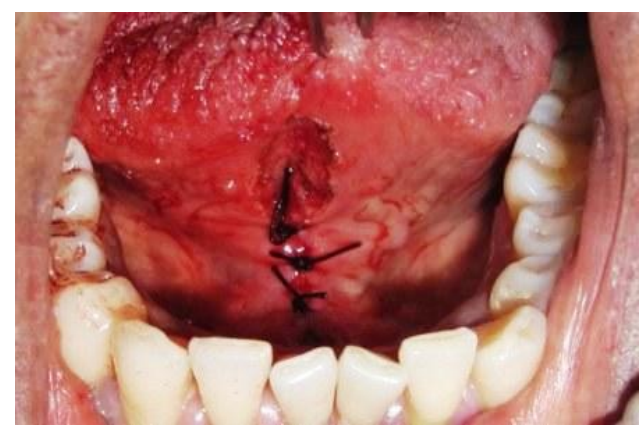

Figure 4. Approximation of wound with sutures.

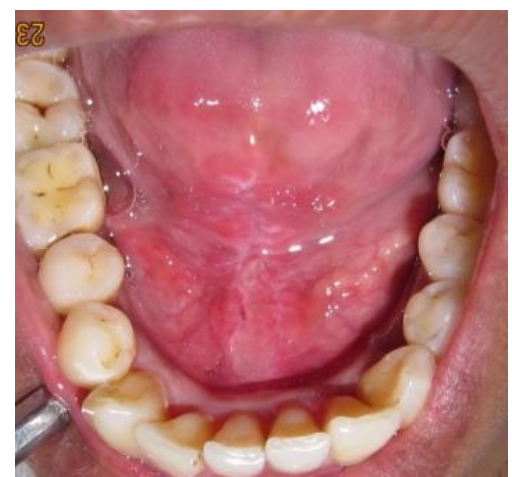

Figure 5. Healing after three months. 


\section{Conclusion}

Tongue-tie is in most cases a relatively harmless condition and the treatment if needed is often relatively simple and safe. Lingual frenectomy procedures are more challenging than labial frenectomy procedures due to the hypermobility of the tongue; and the proximity to the submandibular ducts and the richly vascular floor of the mouth. Therefore surgical LASERs provide an added benefit in such cases.

[1]. AF Wallace. Tongue tie. Lancet 1963;2:377-8

\section{References}

[2]. AH Messner. Ankyloglossia: incidence and associated feeding difficulties. Arch Otolaryngol Neck Surg. 2000; 126:36-9.

[3]. DM Laskin. Oral and Maxillofacial surgery, Volume 1. The CV Mosby Company, 1989: page no. 360.

[4]. LA Kotlow. Ankyloglossia (tongue-tie): A diagnostic and treatment quandary. Quintessence Intl 1999;30:259-62.

[5]. SE Fisher, JW Frame. Electrosurgical management of soft tissues and restorative dentistry. Dent clin North Am 1980;24:297-9.

[6]. H Wigdor, J Walsh, JDB Featherstone, S Visuri, et al. LASERs in dentistry. LASERs Surg Med 1995;16:103-33.

[7]. H Bader. Use of LASERs in periodontics. Dent Clin North Am 2000;44:779-92. 